\title{
CONTEÚDO E FORMA, RAZÃO E SENSIBILIDADE NO PROCESSO DE ENSINO-APRENDIZAGEM
}

\author{
CONTENIDO Y FORMA, RAZÓN Y SENSIBILIDAD EN EL PROCESO DE \\ ENSEÑANZA-APRENDIZAJE
}

\section{CONTENT AND FORM, REASON AND SENSIBILITY IN THE TEACHING-LEARNING PROCESS}

\author{
Luciane NEUVALD ${ }^{1}$ \\ Aliandra Cristina Mesomo LIRA ${ }^{2}$
}

RESUMO: Pretende-se refletir sobre a relação entre conteúdo e forma a partir do par conceitual razão e sensibilidade. Entende-se que a experiência estética abre espaço para o diálogo entre os dois elementos que compõem o último par conceitual, contribuindo para que a relação entre conteúdo e forma resista ao dualismo e à espetacularização do ensino. A análise fundamentada no referencial teórico adorniano vislumbra, na arte, a potencialidade formativa e a possibilidade de pensar e conhecer acolhedoramente o objeto de conhecimento. Nesses termos, a experiência estética enquanto experiência formativa pressupõe a negação da lógica instrumental e a ênfase na lógica emancipatória.

PALAVRAS-CHAVE: Adorno. Razão e sensibilidade. Ensino-aprendizagem.

RESUMEN: Se pretende reflexionar sobre la relación entre contenido y forma a partir del par conceptual razón y sensibilidad. Se entiende que la experiencia estética abre espacio para el diálogo entre los dos elementos que componen el último par conceptual, contribuyendo para que la relación entre contenido y forma resista al dualismo y a la espetacularización de la enseñanza. El análisis fundamentado en el referencial teórico adorniano vislumbra, en el arte, la potencialidad formativa y la posibilidad de pensar y conocer de forma acogedora el objeto de conocimiento. Así, la experiencia estética como experiencia formativa presupone la negación de la lógica instrumental y el énfasis en la lógica emancipadora.

PALABRAS CLAVE: Adorno. Razón y Sensibilidad. Enseñanza-aprendizaje.

ABSTRACT: The intention is reflect on the relationship between content and form from the conceptual couple reason and sensibility. It is understood that the aesthetic experience open space for dialogue between the two elements that make up the last couple conceptual, contributing to the relationship between content and form resist the

\footnotetext{
${ }^{1}$ Professora Adjunta do Departamento de Pedagogia e do Programa de Pós-graduação em Educação da Unicentro. Email: luneuvald@terra.com.br

${ }^{2}$ Professora Adjunta do Departamento de Pedagogia e do Programa de Pós-graduação em Educação da Unicentro. Email: aliandralira@gmail.com
} 
dualism and the spectacle of education. The analysis based on the theoretical framework envisions Adorno, in the art, the formative potential and the possibility of thinking and knowing warmly the object of knowledge. In these terms, the aesthetic experience as a formative experience presupposes the denial of instrumental logic and the emphasis on the emancipatory logic.

KEYWORDS: Adorno. Reason and sensibility. Teaching- learning.

\section{Introdução}

Pretende-se refletir sobre a relação entre conteúdo e forma a partir do par conceitual razão e sensibilidade. Entende-se que a experiência estética abre espaço para o diálogo entre os dois elementos que compõem o último par conceitual, contribuindo para que a relação entre conteúdo e forma resista ao dualismo e à espetacularização do ensino. Na primeira seção, discute-se a relação conteúdo e forma, constituinte do processo de ensino-aprendizagem, objeto de estudo da Didática. Essa relação é analisada a partir do par conceitual: razão e sensibilidade. Parte-se do pressuposto de que o processo de ensino-aprendizagem, desde sua entrada para o campo epistemológico, no século XVII, com a Didática Magna, enfatizou a razão de um aspecto dominador, aplicada à produção nos moldes do instrumentalismo. Nessa perspectiva, o componente sensível mantém uma relação direta com o mundo, pois dele provém o conhecimento, que é compreendido como uma aquisição exterior e imediata, sem comportar a relação interrogativa entre a realidade e o pensamento. Assim, destituise a sensibilidade que caminha no sentido inverso, ou seja, a que acolhe o objeto e busca a não reconciliação entre o pensamento e a realidade, a que preza pela cognoscibilidade, mas não se divorcia da afetividade, a que admite a interação entre o sujeito e o objeto do conhecimento.

Esses pressupostos convergem para a necessidade de se discutir, inicialmente, a constituição histórica da Didática enquanto campo epistemológico, a fim de revelar o seu vínculo com a razão instrumental, que compreende o elemento sensível a partir do uso dos sentidos como instrumento de dominação do objeto.

A segunda e última seção busca na experiência estética e na obra de arte, concebidas a partir da perspectiva adorniana, o fundamento de um processo de ensino- 
aprendizagem em que conteúdo e forma comportem a razão afeita à sensibilidade, comprometida com a razão emancipatória, de cunho formativo.

\section{A relação conteúdo e forma, razão e sensibilidade na didática}

A preocupação com o ensino mais agradável e menos enfadonho esteve presente em Comenius, no século XVII, quando, através de sua obra Didática Magna, o ensino entra para o campo epistemológico. Seu desafio consistiu em encontrar um caminho seguro para ensinar e aprender com facilidade, solidez e de maneira rápida e concisa. Segundo o autor (2006, p. 202), esse empreendimento seria pesado e laborioso se não fosse possível reduzir o tempo e o trabalho, conforme exemplo dos tecelões e moleiros que abreviavam suas atividades com o auxílio da arte, que não prescindia da força. $\mathrm{Na}$ escola, o elemento que reduziria a força, seria o método, mais especificamente aquele de característica única, que permitisse ensinar ao mesmo tempo todos os alunos da mesma classe. Comenius questionava o uso de muitos livros dentro e fora da escola, pois distrairiam o espírito. A mesma crítica era válida para o uso de métodos diferenciados para as artes e línguas. O método único defendido por Comenius é chamado de método natural, pois se baseia nos exemplos da natureza que, por sua vez, não se atém às coisas inúteis.

\footnotetext{
Para que servem as coisas supérfluas? A quem aproveita aprender coisas que não proporcionam vantagem alguma a quem as sabe, nem prejuízo a quem não as sabe? Ou que, com o progredir da idade, deverão ser desaprendidas ou esquecidas em meio a todas as ocupações? Nossa breve vida é tão cheia de compromissos que é possível ficarmos totalmente ocupados sem perder nem mesmo um minuto em bisbilhotices. A escola tem a missão de ocupar os jovens só com coisas sérias (COMENIUS, 2006, p.185).
}

A concepção utilitarista, fortemente marcada no pensamento de Comenius, segundo Gasparin (1997, p. 51-55), traduz o espírito da época em que ele viveu, os avanços científicos e as necessidades sociais que marcaram o século XVII. Além disso, ela expressa a alteração das exigências envolvidas na salvação do homem. Se, para o homem medieval, a conquista do céu tinha como instrumento a salvação, no contexto burguês, ela se ancorava no conhecimento, na instrução, no trabalho, ou seja, na ação material. 
Para racionalizar, organizar e dar eficiência e produtividade ao ensino, o método idealizado por Comenius sustentava-se em três pilares: facilidade, solidez e rapidez. No primeiro, aparece nos seguintes termos: "É para a utilidade imediata" (2006, p. 165); no princípio da solidez: "Se só forem estudados assuntos de inquestionável utilidade" (2006, p. 184). No terceiro princípio, referente à rapidez, Comenius destaca que

[...] no futuro será preciso remover todos os empecilhos e atrasos, utilizando apenas aquilo que leve diretamente à meta, sem delongas, ou seja (segundo voz comum), sem usar muitos meios quando bastarem poucos para atingir o objetivo (COMENIUS: 2006, p. 206).

Para alcançar tal propósito, seu método inspirou-se na proposta baconiana de criação de um método à prova de qualquer cientista. No contexto educacional, pressupunha um método à prova de qualquer professor, aluno e contexto social. Nessa perspectiva, a cientifização do ensino equivalia à homogeneização e ao controle, viabilizados pelo uso da razão aplicada ao processo de trabalho capitalista. Assim, as proposições comenianas convergem com a ideia que associa o ensino ao ofício e às artes, cujo significado, no século XVII, comportava o sentido de divisão do trabalho. Comenius (2006, p.53-54) reconhece que o fim último do homem é a bem-aventurança com Deus, porém, subordina esse fim aos dons da racionalidade (capacidade de indagar, nomear, classificar, entender e conhecer, inclusive aquele que diz respeito às técnicas) e ao poder do homem sobre as outras criaturas, por agir em benefício próprio, "comportando-se como rei das criaturas".

$\mathrm{O}$ método único, por tentar racionalizar o processo educativo equiparando-o à organização industrial e produtiva, abre a possibilidade de que os princípios formativos cedam lugar aos imperativos econômicos. Gruschka (2008) e outros teóricos defendem a ideia de que a indústria cultural teria dado origem a mais antiga didática - aquela que se constituiu a partir do século dezessete - quando os conteúdos da formação e da ciência cederam lugar aos imperativos do consumo, assumindo a forma simplificada e sistematizada a partir do livro didático, que realiza para o sujeito a tarefa que o esquematismo kantiano lhe atribuía, ou seja, a organização do conhecimento. Dessa forma, trabalho de construção conceitual seria antecipado e sistematizado pelo livro didático e por todo o aparato pedagógico, fundamentados na lógica da indústria cultural. Portanto, Gruschka (2008) tem razão em defender a relação entre a indústria cultural e a didática, pois isso significa que a expansão escolar, na tentativa de derramar as luzes da razão, trilhou os caminhos do obscurecimento, semelhante àquele trilhado pelo mito, 
cujo pensamento esclarecido procurava escapar. A formação nos moldes tradicionais era incompatível com a ideia de massificação da cultura.

A didática nasce com uma necessidade de síntese e, portanto, com uma necessidade de unificar, simplificar e facilitar a divulgação da ciência. Nesse contexto, objetividade e clareza passam a nortear a consecução dos referidos objetivos, no entanto, uma figura clara possui um aspecto esotérico, que necessita da inclusão do interlocutor. Assim, a compreensão se efetua naquilo que é preciso compreender primeiro e que se enquadra em esquemas preexistentes e na familiaridade. Tais condições, segundo Adorno (1993, p. 125), ameaçam corromper a linguagem. A preocupação com a linguagem clara e com a acessibilidade de seu conteúdo coloca em risco a profundidade do objeto e pressupõe a necessidade de fazer "concessões ao consumo". Essa forma de tratar a linguagem traz implicações para o pensamento, especialmente quando se considera o vínculo entre ambos. A relação entre adaptação da linguagem e a diminuição do esforço compreensivo é algo compatível com os moldes da indústria cultural, que precisa adequar os processos de produção aos de recepção. Além disso, a própria velocidade na qual ela opera é compatível com a simplificação e a ausência da reflexão.

As transformações ocorridas no século XVII, quando a Didática ganha estatuto epistemológico e, segundo Cambi (1999, p. 284), afirma sua autonomia em relação à filosofia e teologia, impulsionam o desenvolvimento do processo de industrialização. Nele, as forças humanas são substituídas pelas forças da natureza e a ciência é fundamental para os processos de produção, cuja forma fragmentada, segundo Freitas, implica em um privilégio das ciências naturais e na dificuldade de se estabelecer a interdisciplinaridade.

Em consequência, as ciências sociais atrofiam-se, tanto em termos metodológicos como em resultados práticos. Abre-se um perigoso fosso entre o conhecimento das forças da natureza e o conhecimento do homem. A ciência converte-se em força potencial destrutiva (FREITAS, 1995, p. 107).

Essa forma de organização da ratio burguesa afetou a filosofia, segundo Adorno (2009, p. 27), conferindo-lhe uma característica antinômica, pois, na tentativa de compreender e alcançar a objetividade, a ratio se impôs como sistema, submetendo-a a seus axiomas e parâmetros de identidade, exigindo a classificação como condição do conhecimento e eliminando as determinações qualitativas. 
A ratio burguesa propôs-se produzir a partir de si mesma a ordem que tinha negado no exterior. Todavia, enquanto uma ordem produzida, essa não é mais ordem alguma; por isso, torna-se insaciável. O sistema era uma tal ordem gerada de maneira racional e insensata: algo posicionado que se apresenta como algo em si. Ele precisou transpor a sua origem para o interior do pensamento formal, cindido de seu conteúdo; ele não podia exercer de outro modo o seu domínio sobre o material. O sistema filosófico foi desde o início antinômico. Nele, o ponto de partida fundiu-se com a sua própria impossibilidade; no início da história dos sistemas modernos, justamente essa impossibilidade condenou cada um deles a ser aniquilado pelo seguinte. A ratio que, para se impor como sistema, eliminou virtualmente todas as determinações qualitativas às quais se achava ligada caiu em uma contradição irreconciliável com a objetividade que violentou, pretendendo compreendê-la. Ela se distanciou tanto mais amplamente dessa objetividade quanto mais plenamente a submeteu a seus axiomas, por fim, ao axioma da identidade (ADORNO, 2009, p. 27).

Assim, conforme ressalta Adorno, na Dialética negativa (2009, p. 19), não cabe à filosofia proceder de forma exaustiva como a ciência, não lhe cabe reduzir os fenômenos a um número mínimo de proposições e nem o heterogêneo a categorias préfabricadas. Sua tarefa consiste em desencantar o conceito, "Alterar essa direção da conceptualidade, voltá-la para o não idêntico, é a charneira da dialética negativa" (ADORNO, 2009, p. 19). Ela gira em torno do reconhecimento da insuficiência da filosofia, especialmente na sua forma tradicional (que vai de Platão a Hegel), que é centrada na onipotência do conceitual e na crença da capacidade do conceito se identificar com a realidade, organizando-a. A contradição na dialética hegeliana vê nos conceitos os sinais do absoluto, conferindo à teoria a capacidade de tudo conhecer, pois se o real é acessível à razão, tudo que é racional é suscetível de concretizar-se na realidade. Disso resulta a crença de que o espírito absoluto é capaz de superar a contradição dialeticamente (JIMENEZ, 1999, p. 170).

Nas palavras de Adorno (2009, p. 13), a contradição na filosofia hegeliana é vista como o não idêntico sob o aspecto da identidade; sendo assim, o que é heterogêneo é mensurado a partir da unidade, já que o princípio da não contradição orienta a dialética. Na concepção adorniana, a contradição é o indício da não verdade da identidade e "A dialética é a consciência consequente da não identidade. Ela não assume antecipadamente um ponto de vista. O pensamento é impelido até ela a partir de sua própria inevitável insuficiência, de sua culpa pelo que pensa” (ADORNO, 2009, p. 13). 
Se na dialética tradicional prevalece a afirmação positiva, Adorno prima pela negatividade, uma vez que a não identidade entre sujeito/objeto, homem/natureza, razão e desrazão consiste no motor da história. Esse fundamento caracteriza a razão emancipatória, que resiste à unidade, à síntese e à totalidade, pois entende que esses pressupostos comungam com a razão de aspecto instrumental.

Arendt (2003, p. 168-170) ressalta que no mundo movido pelo utilitarismo, tudo tem seu uso e serve de instrumento para outra coisa e essa cadeia interminável de meios e fins promove a curta duração e gera ausência de significado, ou seja, de um princípio que justifique a categoria de meios e fins. A utilidade e a serventia como critérios últimos para a vida e o mundo dos homens, segundo a autora, colocam em questão a generalização da experiência da fabricação, sua extensão para o âmbito das relações humanas, que se pautam pelas relações de troca e pela produção de coisas. Nesse contexto, conforme a autora (2003, p.179), o valor das coisas não se produz no isolamento, na própria coisa, mas nas relações sociais, no processo de consumo. Ela cita as obras de arte como objetos únicos, estritamente sem utilidade, cujo valor só pode ser estabelecido arbitrariamente quando expostas ao mercado de trocas. Para galgar o seu lugar no mundo, as obras de arte precisam ser isoladas das exigências e necessidades da vida diária, por isso sua durabilidade é superior à das outras coisas, pois “[...] não estão sujeitas ao uso das criaturas vivas, uso que, na verdade, longe de materializar sua finalidade inerente (como a finalidade de uma cadeira é realizada quando alguém se senta nela), só pode destruí-la" (ARENDT, 2003, p.181).

O aspecto autêntico da obra de arte, que lhe permite escapar da lógica massificadora e de consumo das mercadorias e, sendo assim, também sua característica não conciliadora com a realidade conferem-lhe o aspecto formativo.

\section{Razão emancipatória e ensino-aprendizagem}

Pensar o processo de ensino-aprendizagem e a relação conteúdo e forma a partir do par conceitual razão/sensibilidade pressupõe uma razão emancipatória, que não se adapta às demandas do mundo exterior, ao utilitarismo e ao imediatismo. Tal razão preserva o sentido da formação nos termos da teoria crítica adorniana, que a concebe como um campo de forças entre espírito e natureza, entre transcendência e acomodação. A expressão desse campo de forças se encontra na obra de arte, que, segundo Adorno 
(2006), apesar de substanciada na empiria, nega as determinações nela impressas através de sua forma, "do rigor lógico da sua estruturação". Para ele, o espírito da obra de arte não é apreendido imediatamente, pois ao mesmo tempo em que ele dá forma ao que aparece, modela-se pela aparição: "Se o espírito das obras de arte fosse literalmente idêntico aos seus momentos sensíveis e à sua organização, seria apenas a substância da aparição" (2006, p. 106). Assim, a racionalidade das obras de arte consiste em elaborar mimeticamente os seus enigmas, nos quais se manifesta o seu espírito. O aspecto enigmático das obras de arte, conforme Adorno (2006, p. 149), não resulta de sua composição, mas de seu conteúdo de verdade, obtido pela reflexão filosófica, que permite decifrá-las, pois o que não é figurativo aguarda por sua decifração. Portanto, o componente espiritual das obras é o que as torna mais que aparência e pura facticidade; elas dizem mais que o ente, pois o seu movimento para a verdade é de caráter negativo, ou seja, nelas, o objeto se define de maneira indeterminável e negativamente. Tal característica expressa a relação entre o momento estético e a filosofia, que não lhe é estranha, uma vez que ela permite interpretar a obra de arte, dizer o que ela não consegue dizer, "[...] enquanto que, porém, só pela arte pode ser dito, ao não dizê-lo" (ADORNO, 2006, p.89).

A apresentação - a linguagem - é algo imanente à filosofia, pois objetiva o momento expressivo, mimético-aconceitual, e, abster-se dele e do compromisso com a apresentação, pressupõe para a filosofia o risco de ser assimilada à ciência. Essa ideia é apresentada por Adorno na Dialética negativa (2009, p. 24), a partir da relação entre o dito frouxamente e o mal pensado - o que reforça o vínculo entre conteúdo e forma na obra de arte - na qual não há divórcio entre ambos, pois sua lógica interna lhe confere uma verdade imanente. Sendo assim, não há arbitrariedade entre os seus elementos: todos eles convergem para a sua composição, ao contrário da lógica dos produtos da indústria cultural, que busca adequar forma e conteúdo aos interesses exteriores. Os produtos culturais, e neles se incluem as obras de arte e os conteúdos que compõem a cultura escolar, ao se deixarem modelar pelos aspectos exteriores, perdem muito do olhar contemplativo e da sua verdade interna, guiando-se pela lógica dos equivalentes que os converte em objeto de consumo e, dessa forma, assumem aspecto assimilável, simplificado e ordenado. Nessas condições, prevalece a razão comandada pela lógica instrumental que não se dispõe ao olhar minucioso, que tudo classifica e generaliza.

A defesa do caráter formativo da cultura, em Adorno (2003, p. 65), é reafirmada quando há o destaque para a necessidade de se salvar "no objeto um pouco do repouso 
do dia de sua criação"; pois o universal não é atingido encurtando-se o caminho para se chegar até ele, mas quando passa pelo "impenetrável" e não pela "conformidade abstrata". Ao se referir ao universal da beleza, Adorno (1993, p. 65) afirma que ela persegue a particularidade e o esforço contemplativo, pois "O olhar que se perde nesta única beleza é um olhar sabático".

Na Mínima Moralia (1993, p. 88), Adorno ressalta a perversão da linguagem ao priorizar a expressão vaga, extraída de esquemas preexistentes; cuja compreensão recai sobre a familiaridade. Para contrapô-la, ele menciona a expressão rigorosa, que pressupõe o esforço conceitual e a suspensão dos juízos habituais. No entanto, o esclarecimento burguês primou pela redução do heterônomo a grandezas abstratas, capturando heterogeneidade pela unidade, pelo caráter antecipatório, pela factualidade que busca igualar o pensamento à realidade, expressando a violência que passa a compô-lo. Ao perseguir a clareza, o pensamento se orienta pelo pressuposto de não deixar resto algum, que nada mais é que o pressuposto da troca de equivalentes, da calculabilidade e da racionalidade técnica mencionados por Horkheimer e Adorno, na Dialética do esclarecimento (1985). A orientação dada pelo referido pressuposto, conforme Adorno menciona na Minima Moralia (1993), iguala a clareza do objeto à concessão ao consumo, à corrupção da figura pela inclusão do interlocutor. A linguagem clara persegue a comunicabilidade e essa, segundo o autor, desconfia das coisas que não são extraídas de modelos preexistentes: "Apenas aquilo que elas não precisam compreender primeiro é tido como compreensível; só aquilo que em verdade, é alienado, a palavra cultivada pelo comércio, é capaz de tocá-los como algo familiar" (ADORNO, 1993, p. 88). Essa característica da comunicabilidade desperta a desconfiança de Adorno quanto ao seu critério de verdade.

O critério do verdadeiro não é a sua comunicabilidade imediata a qualquer um. É preciso resistir à compulsão quase universal a confundir a comunicação daquilo que é conhecido com aquilo que é conhecido, e mesmo a colocá-la se possível em uma posição mais elevada, uma vez que atualmente cada passo em direção à comunicação liquida e falsifica a verdade (ADORNO, 2009, p. 43).

A possibilidade de escapar do falseamento inerente à lógica da comunicabilidade é encontrada na experiência estética, pois a obra de arte autêntica contradiz o pronunciamento. Sua essência enigmática, expressa a partir da linguagem cifrada, produz semelhanças e oportuniza a experiência mediática e formativa que se realiza a 
partir do distanciamento e da tensão com o objeto do conhecimento. A obra de arte, ao primar pela não-identidade, permite resistir aos apelos totalitários e deformadores da consciência advindos da indústria cultural que, ao proceder dessa forma, neutraliza os aspectos formativos dos objetos culturais.

\begin{abstract}
A ideologia cultural conservadora, que vê uma oposição simples entre o esclarecimento e a arte, é falsa também no sentido de que desconhece a dimensão do esclarecimento presente na gênese do belo. $\mathrm{O}$ esclarecimento não dissolve apenas todas as qualidades às quais o belo é inerente, mas põe ao mesmo tempo pela primeira vez a qualidade do próprio belo (ADORNO, 1993, p. 196).
\end{abstract}

Na concepção adorniana, a sensibilidade não se opõe à razão, a beleza não se opõe ao conhecimento; ambas conservam o olhar enigmático e sabático, que confere à contemplação o vínculo entre a experiência estética e a cognitiva. A contemplação não se limita à apreciação e à fruição, pois, ao resguardá-las, promove as atitudes do deslocamento e do estranhamento, próprias do sujeito disposto a acolher o objeto e a interagir com ele. Dessa forma, o indivíduo sai da zona de conforto e, no lugar das experiências tranquilizantes e identificatórias advindas da indústria cultural, abre-se para viver a angústia própria do processo formativo, cuja característica inquietante e interrogativa fortalece a sua autonomia, entendida enquanto capacidade de autorreflexão crítica.

A possibilidade de a obra de arte fortalecer a autonomia do pensamento, enfraquecida quando ele se submete ao controle social do desempenho e à solução de tarefas, coloca na ordem do dia a tese adorniana que reconhece a dimensão do esclarecimento no belo e lança o desafio de pensarmos a formação a partir do par conceitual razão e sensibilidade - o que possibilitaria resistir à dicotomia conteúdo e forma, que, na tentativa de facilitar a tarefa pedagógica tende a tratá-la a partir de artificialismos e estratégias vazias. Entende-se que a tarefa pedagógica é árdua, retirarlhe o aspecto dramático compromete o seu sentido formativo que a ele se vincula. Nesse sentido, a tarefa pedagógica resiste às tentativas de unidade e síntese, pois seu papel formativo só se efetiva no olhar sabático e interrogativo. Apesar de não conservar as projeções tranquilizantes da indústria cultural, o processo formativo pode ser belo e alegre na medida em que toma como conteúdo e forma a experiência estética.

\title{
Considerações finais
}


A escola moderna procurou administrar os sentidos e, sendo assim, eles foram tratados no âmbito da razão instrumental e científica. Nesse sentido, a apreensão sensível do objeto deveria corresponder a uma imagem fiel dos elementos empíricos, ou seja, à identidade. Pensar a relação entre sensibilidade e a razão a partir da experiência estética, do contato com as obras de arte e com objetos culturais que resistem aos apelos simplificadores e espetacularizantes, pressupõe uma nova relação do sujeito com o objeto do conhecimento. Essa nova relação resiste ao aligeiramento, uma vez que pressupõe um tempo mais prolongado e um contato mais íntimo com objeto, a fim de desvendar os seus enigmas e descobrir outros, salvaguardando a especifidade da experiência estética, a não-identidade, que lhe garante as qualidades formativas. Além disso, a formatividade da experiência estética, com sua natureza complexa e aberta, permite integrar os conhecimentos sem lançar mão de instrumentalismos pedagógicos, afeitos a estratégias e métodos que tentam sobrepor a forma na tentativa de garantir o conteúdo.

\section{REFERÊNCIAS}

ADORNO, T. W; HORKHEIMER, M. Dialética do esclarecimento: fragmentos filosóficos. Tradução de Guido Antonio de Almeida. Rio de Janeiro: Zaar, 1985.

ADORNO, T. W. Minima Moralia: reflexões a partir da vida danificada. Tradução de Luiz Eduardo Bicca. São Paulo: Ática, 1993.

ADORNO, T. W. Experiência e criação artística. Lisboa: Edições 70, 2003.

ADORNO, T. W. Teoria Estética. Tradução de Artur Morão. Lisboa: Edições 70, 2006.

ADORNO, T. W. Dialética negativa. Tradução de Marco Antonio Casanova. Rio de Janeiro: Zaar, 2009.

ARENDT, H. A condição humana. Tradução de Roberto Raposo. Rio de Janeiro: Forense Universitária, 2003.

COMENIUS, J. A. S. Didática Magna. Tradução de Ivone Castilho Benedetti. São Paulo: Martins Fontes, 2006.

FREITAS, L. C de. Crítica da Organização do Trabalho Pedagógico e da Didática. São Paulo: Papirus, 1995. 
GASPARIN, J. L. COMÊNIO: a emergência da modernidade na educação. Petrópolis: Vozes 1997.

GRUSCHKA, A. Escola, Didática e Indústria Cultural. In: DURÃO, F. A; ZUIN, A; VAZ, A. F (Orgs.). A indústria cultural hoje. São Paulo: Boitempo, 2008, p.173-183.

JIMENEZ, M. O que é Estética. Tradução de Fulvia M. Moretto. São Leopoldo: UNISINOS, 1999.

\section{Como referenciar este artigo}

NEUVALD, Luciane; LIRA, Aliandra Cristina Mesomo. Conteúdo e forma, razão e sensibilidade no processo de ensino-aprendizagem. Revista Ibero-Americana de Estudos em Educação, Araraquara/SP, v. 11, n. 3, p.1331-1342, 2016. Disponível em: <https://dx.doi.org/10.21723/riaee.v11.n3.7601>. E-ISSN: 1982-5587.

Submetido em: 04/03/2015

Aprovação final em: 29/07/2016 